\title{
Encruzilhadas da Democracia e da Saúde Mental em Tempos de Pandemia
}

\author{
Magda Dimenstein ${ }^{1}$ \\ ${ }^{1}$ Universidade Federal do Rio Grande do Norte, \\ $R N$, Brasil.
}

\author{
Ana Carolina Rios Simoni ${ }^{1}$ \\ ${ }^{1}$ Universidade Federal do Rio Grande do Norte, \\ RN, Brasil.
}

\author{
Mario Francis Petry Londero ${ }^{1}$ \\ ${ }^{1}$ Universidade Federal do Rio Grande do Norte, \\ RN, Brasil.
}

Resumo: Esse artigo visa abordar a relação entre democracia, saúde mental e pandemia. Para tanto, convida o leitor, na primeira parte do texto, a revisitar o assombro da chegada da pandemia da Covid-19 por meio de um filme, cujas personagens colocam em cena posições subjetivas distintas que carregam a potência de interpelar nosso lugar nos cenários necropolíticos da crise sanitária brasileira. Na segunda parte do texto, algumas encruzilhadas da democracia e da saúde mental na atualidade são explicitadas, a exemplo da propagação de discursos antidemocráticos e do recrudescimento das fragilidades da Rede de Atenção Psicossocial. Na última parte do escrito, compartilha-se uma experiência de Educação Permanente em Saúde em curso junto a trabalhadores da Rede de Atenção Psicossocial e da Atenção Primária à Saúde, e se desenvolve uma tentativa de reposicionar as balizas para a ação ético-política no campo da saúde mental contra a paralisia e a anestesia agenciadas pela lógica capitalista do estado necroliberal, que não raro engessa os afetos, os corpos e os atos dos trabalhadores da saúde no cotidiano das práticas.

Palavras-chave: Democracia, Pandemia, Saúde Mental, Atenção Psicossocial, Educação Permanente em Saúde.

\section{Crossroads of Democracy and Mental Health in Times of Pandemic}

\begin{abstract}
This article addresses the relationship between democracy, mental health and pandemic. To this end, it invites the reader, in the first part of the text, to revisit the amazement of the arrival of the Covid-19 pandemic by means of a film, whose characters place on the scene distinct subjective positions that carry the power to challenge our place in the necropolitical scenarios of the Brazilian health crisis. In the second part of the text, some of the crossroads of democracy and mental health today are explained, following the example of the propagation of anti-democratic discourses and the recrudescence of the weaknesses of the Psychosocial Care Network (RAPS). In the last section, we share an experience of Permanent Health Education in progress with workers of RAPS and Primary Health Care, and the attempt to reposition the goals for ethical-political action in the field of mental health against paralysis and anesthesia, enacted by the capitalist logic of the necroliberal state, which not infrequently engages the affections, bodies, and acts of health workers in daily practices.
\end{abstract}

Keywords: Democracy, Pandemic, Mental Health, Psychosocial Care, Permanent Health Education. 


\title{
Encrucijadas de la Democracia y la Salud Mental en Tiempos de Pandemia
}

\begin{abstract}
Resumen: Este artículo tiene como objetivo abordar la relación entre la democracia, la salud mental y la pandemia. Para ello, invita al lector, en la primera parte del texto, a revisar el asombro de la llegada de la pandemia de Covid-19 por medio de una película, cuyos personajes ponen en escena distintas posiciones subjetivas que tienen el poder de desafiar nuestro lugar en los escenarios necropolíticos de la crisis sanitaria brasileña. En la segunda parte trata de explicar algunas de las encrucijadas de la democracia y la salud mental en la actualidad, como ejemplo la propagación de los discursos antidemocráticos y el recrudecimiento de las debilidades de la Red de Atención Psicosocial (RAPS). En la última parte, se comparte una experiencia de Educación Sanitaria Permanente en curso con trabajadores de la RAPS y de la Atención Primaria de Salud, y el intento de reposicionar los objetivos de la acción ético-política en el campo de la salud mental contra la parálisis y la anestesia, agenciada por la lógica capitalista del estado necroliberal, que no pocas veces compromete los afectos, los cuerpos y los actos de los trabajadores de la salud en las prácticas cotidianas.
\end{abstract}

Palabras clave: Democracia, Pandemia, Salud Mental, Atención Psicosocial, Educación Sanitaria Permanente.

\section{Introdução}

A chegada da pandemia da Covid-19 ao redor do mundo trouxe a necessidade de adoção global de estratégias de prevenção - em especial de distanciamento social - impactando nos modos instituídos de viver e de se relacionar nas diferentes culturas e territórios. Fomos, todas e todos, em alguma medida, atravessados pela ameaça do contágio e do risco eminente do adoecimento e da morte, por súbitas mudanças nas rotinas de trabalho, de educação, de lazer, de uso dos espaços privados e públicos, nas relações com o próprio corpo e com o dos outros. O humano, que sustenta sua existência, afetiva e materialmente, por meio das relações sociais, viu-se interpelado pela necessidade de tessitura de novas formas de laços e de reordenamento dos pactos sociais vigentes. Sob a égide dessa convocação ética e política, estamos todas e todos. Tarefa intricada e difícil de ser operada coletivamente.

Contudo, em um país socioeconomicamente tão injusto e desigual e culturalmente tão heterogêneo, o desafio de defender a vida, singular e coletiva, se redobra em inúmeras camadas de complexidade que remontam às seculares e inconclusas lutas que marcam nossa história como povo. Lutas por políticas de saúde que reconheçam e operem a inseparabilidade entre saúde e condições de vida; por políticas de proteção social que compreendam e combatam as iniquidades como fator estrutural e estruturante da perpetuação da pobreza; por políticas de saúde mental que incorporem o sentido do cuidado em liberdade no território, considerando perspectivas de gênero e orientação sexual, raça/etnia, geração e classe social; por políticas de inclusão social e equidade que combatam os racismos e sexismos estruturais e institucionais perpetuados cotidianamente.

Deste modo, neste escrito, nos propomos a problematizar a vivência da pandemia, focando nos desafios históricos do campo da Atenção Psicossocial e da Reforma Psiquiátrica brasileira, redobrados na atual conjuntura antidemocrática, de recrudescimento da precarização da vida e relançados nos espaço-tempos de emergência e distanciamento social trazidos pela pandemia. Interessa-nos colocar esses desafios, antigos e emergentes, em diálogo com as experiências de trabalhadores da Rede de Atenção Psicossocial (RAPS) compartilhadas nos contornos de uma proposta de Educação Permanente em Saúde (EPS) na modalidade remota, proposta por meio de uma parceria interinstitucional entre o Departamento de Psicologia da UFRN, a Coordenação Municipal de Saúde Mental de Natal/RN e a Coordenação Estadual de Saúde Mental do Rio Grande do Norte.

Na primeira parte do texto, o leitor é convidado a revisitar o assombro da chegada da pandemia da Covid-19 por meio de um filme cujas personagens 
colocam em cena posições subjetivas distintas, que carregam a potência de interpelar nosso lugar nos cenários necropolíticos da crise sanitária brasileira. Na segunda parte, os desafios históricos repostos à democracia e à saúde mental em tempos de pandemia são explicitados, analisando processos, visibilizando percalços e reafirmando princípios para darmos novos passos-mundo. Na terceira e última parte do escrito, compartilhamos a experiência de EPS na RAPS antes mencionada, ao passo que reposicionamos balizas para a ação ético-política no campo da saúde mental contra a paralisia e a anestesia agenciadas pela lógica capitalista do estado necroliberal, que não raro engessam os afetos, os corpos e os atos dos trabalhadores da saúde no cotidiano das práticas.

\section{Interpelações da pandemia para uma vida não fascista ${ }^{1}$}

\section{Temos de produzir alguma coisa que ainda não existe e que não sabemos o que será.}

(Foucault)

O filme Melancolia, de Lars Von Trier (2011), nos conta sobre o antagonismo dos sentidos de vida de duas irmãs. $\mathrm{O}$ diretor divide a película em dois momentos, cada um com o nome de uma das respectivas personagens. A parte um chama-se Justine, a mais nova das irmãs, protagonista que na sociedade da imagem e do consumo, tomado como valor universal de felicidade, personifica aquela que fura, com sua falta de sentido, toda a convocação contemporânea de produção e de sucesso. Em um dado momento da primeira parte do filme ocorre o ritual de casamento de Justine, que foi um desastre, tal qual suas outras relações. Justine sente que lhe impõem o uso de uma máscara teatralizante, formatada com um sorriso para esconder um rosto acinzentado. Ela se nega a usar tal máscara e desmascara toda a malcheirosa hipocrisia presente em suas relações familiares.
Justine e sua irmã Claire são o avesso uma da outra. A cada encontro, Claire se assombra com o desdém da irmã quanto a tudo que ela valoriza, no caso, uma vida mínima vendida em mercadorias, na qual tudo ganha uma embalagem atrativa, uma promessa de gozo. Justine resiste, insiste em não acreditar nessa vida regida pelas imagens-fluxos do mercado. Para alguns, ela estaria em uma posição melancólica, no sentido de uma completa desidentificação com o Outro $^{2}$ capital, restando apenas um vazio inenarrável. Não existe nada que pareça alimentar Justine de sentidos nisso que se chama vida. Desânimo de viver, vazio existencial que se nega a se alimentar do que é oferecido pela lógica de consumo capitalista.

Na segunda parte do filme, a partir de um evento inesperado, as trajetórias das personagens vão tomando diferentes direções. Para Claire, predomina o desmoronar dos territórios existenciais tão bem edificados. Seus sentidos vão se esvaziando à medida que um planeta inesperado colide com a Terra, destruindo seu mundo. Nessa parte do filme, Claire vai ficando cada vez mais desesperada, pois perdia o controle de uma vida sustentada em verdades compradas, em convenções sociais que davam um norte de maneira sobreimplicada ${ }^{3}$. Claire era protegida por um véu conservador e consumista que, de maneira súbita, lhe foi retirado. Desamparada como uma cordeirinha sem pastor, cada minuto da segunda parte do filme mostra sua incapacidade de abraçar esse destino que se impôs bruscamente. Como uma marionete, que só se mexe pelas mãos de um Outro trajado de senhor, acaba paralisada para lidar com a falência do que a governa e que lhe oferecia, até então, um caminho restrito, mas seguro de seguir. Mortifica-se, antes mesmo do mundo desaparecer.

Contudo, para Justine, a falência dos sentidos do mundo a partir da aproximação de seu fim a enche de potência. Com absoluta coragem, entrega-se a esse inesperado que faz despencar mundos e começa a habitar-se de promessa de vida. Justine, antes melancólica, se transfigura em uma personagem trágica-utópica:

\footnotetext{
${ }^{1}$ Trata-se de uma problematização ético-política operada por Foucault (1996) em relação às práticas de subjetivação, às montagens subjetivas no mundo contemporâneo, ancoradas, sobretudo, na docilidade, obediência e sujeição às forças estabelecidas. Para o autor, a arte de viver é contrária a todas as formas de fascismo, essa lógica que nos torna "caídos de amores pelo poder", é acompanhada de certos princípios no sentido de construir modos de vida libertários e fazer dela uma obra de arte.

${ }^{2}$ Para Lacan (1953-1954/2009), o eu do sujeito constitui-se inicialmente em uma experiência de linguagem endereçada a um tu, o que supõe, então, uma intrínseca relação junto ao Outro, que aqui caracterizamos como trajado por uma discursividade capitalista.

${ }^{3}$ A sobreimplicação é um conceito da análise institucional e diz respeito a um modo do sujeito estar no mundo, no caso, de uma maneira a não perceber os atravessamentos institucionais que estão em seu discurso sobre como se portar na própria vida (Passos \& Barros, 2009).
} 
nunca amou tanto um destino ${ }^{4}$ que a invadia e, ao mesmo tempo, varria com força o terreno que sempre habitou, no caso, o da negação do lugar da sujeição, enlaçado pelas convenções sociais. Nunca acreditou no mundo que a ela vendiam, sua transferência com esse discurso do capitalista há muito tempo estava liquidada ${ }^{5}$. Vislumbrar sua decadência, o desaparecimento de um enlace que somente a enforcava, trazia o maior dos alívios para Justine.

Esse clássico do cinema nos pareceu muito instigante para pensar as circunstâncias que se abatem sobre nossa vida na atualidade, pois supomos que passamos por algo bastante similar. O mundo parece desmoronar sobre nossas cabeças, não por um planeta em colisão com a Terra, mas por um vírus chamado Covid-19. O desamparo ${ }^{6}$ recrudesceu, acionando mecanismos de defesa primitivos, formas de subjetivação individualizantes e o descolamento dos laços sociais (Freud, 1930/2010). Não à toa, alguns pastores se negam a fechar seus templos e mitos resistem em pisar no terreno do bom senso, ficam desesperados, negando a extensão da pandemia, a gravidade da enfermidade, as formas de contágio e, especialmente, a impossibilidade de tocar a vida nos mesmos padrões anteriores. Seus seguidores assumem uma postura negacionista e um individualismo egocêntrico que se sustentam no discurso da liberdade de expressão e de circulação. Resistem às medidas protetivas como o distanciamento e o uso de máscaras e depreciam os esforços coletivos no sentido de contenção da transmissão do vírus.

Nesse cenário, o espanto tomou forma, desertificou as paisagens cotidianas que até então eram modelos de vida e escancarou as portas para discursividades cada vez mais perversas ou delirantes, conectadas às lógicas capitalistas, nacionalistas, patriarcais e racistas. O registro do real lacaniano ${ }^{7}$ parece ter emudecido as possibilidades discursivas; uma ressaca marítima transbordou às margens da praia e levou consigo todas as pegadas (Souza, 2008) e os direcionamentos que sustentavam os caminhantes. "Fragilidade repentina, perplexidade diante da imprevisibilidade, sensação de risco de aniquilação e surpresa pela abrupta transformação do mundo são algumas das locuções que temos escutado no contexto desta pandemia", dizem Verztman e Romão-Dias (2020, p. 274) ao se referirem ao cotidiano da clínica nesses tempos.

Fala-se também na produção de uma certa hipocondria social generalizada pelo planeta, caracterizada pela hiper vigilância do corpo e medo do contágio; pelo aparecimento de sintomas associados ao transtorno do pânico, manifestações somáticas variadas, problemas do sono e uso abusivo de medicamentos ou automedicação, inclusive, dos não recomendados ou sem comprovação de eficácia clínica como a hidroxicloroquina. A caixa de Pandora foi aberta e a possibilidade de enlouquecimento parece ser nossa maior ameaça, tal como vivida pela personagem Claire, e tão amplamente explorada pela mídia que a todo dia destaca a "insanidade mental" e a "loucura" produzida, em particular, pelo distanciamento físico, pela exigência de cumprimento das medidas de proteção, pela ausência de vacina até o presente momento e pelas incertezas quanto ao futuro pós-pandemia.

A Covid-19 invadiu o mundo e obrigou massas populacionais a se recolherem, impôs seu ritmo descompassado à sociedade capitalista. Nações fecharam suas fronteiras e a reabertura tem reacendido focos de contágio, a indústria e o consumo de bens e serviços estão longe de voltarem ao patamar anterior. Há quem diga que esse cenário está propício à derrubada do capitalismo e à invenção de um novo modelo econômico-político-social comunista.

\footnotetext{
${ }^{4}$ Em Nietzsche (2011), amar o destino diz respeito ao que o autor enuncia como “amor fati”. Inspirado nas tragédias gregas, o filósofo propõe a afirmação da vida em ato, do esquecimento do que foi e do que virá, de maneira que o homem possa estar inteiramente voltado para sua ação presente sem ressentimento e sem se importar com os resultados e rumos que o destino lhe pregará.

${ }^{5} \mathrm{~A}$ transferência diz respeito à carga afetiva depositada e trocada nas relações que o sujeito trama em sua própria vida, não sendo diferente quando falamos das relações sociais imersas no capitalismo, com o qual se produz um circuito afetivo de produção e consumo. Safatle (2017), com base nos textos psicanalíticos, pontua que uma estratégia de resistência frente ao capitalismo é forjar uma liquidação da transferência junto a esta instituição que constitui o Outro e que nos assujeita em seu discurso.

${ }^{6}$ O desamparo, segundo Freud (1930/2010), é a condição irremediável do humano, oriunda de sua necessidade de realizar trocas com o mundo e da extrema dependência da ajuda de outros. O sentimento de desamparo é estruturante do psiquismo, sustenta-se numa relação de tensão entre o desejo e a lei, exigindo renúncias pulsionais.

${ }^{7}$ Os três registros que constituem a realidade humana são: o simbólico, o imaginário e o real, sendo esse último compreendido como aquilo que não vinga nomes, lugar sinalizado pela angústia, vazio de significantes, o inapreensível que resiste em ser furado pelo registro do simbólico, mas que também é fonte de invenção do sujeito (Lacan, 1975-1976/2007).
} 
O filósofo esloveno Zizek é um dos mais entusiastas dessa ideia e, em sua entrevista "O nascimento de um novo comunismo" para Paiva (2020), salienta as intervenções estatais que estão ocorrendo na economia e nas políticas públicas e o quanto tais atos podem nos mostrar que um outro modo de operar o sistema é possível.

Já para Byung-Chul Han (2020), esse momento de pandemia só fez aumentar e atualizar, à maneira chinesa, os mecanismos de controle do estado sobre a população. $\mathrm{O}$ autor sul-coreano comenta o quanto a vigilância digital está completamente legitimada nos países asiáticos e que tais estratégias, possivelmente, serão usadas cada vez mais nos países ocidentais. Temos, então, uma versão repaginada da sociedade de controle deleuzeana aos olhos de Han, na qual o estado utiliza as tecnologias virtuais e os sites de relacionamento para controlar a população. Enfim, de acordo com Wolff, Minella, Lago e Ramos (2020, p. 3), muitas perguntas têm sido postas:

Ocorrerão mudanças estruturais com a superação do capitalismo ultraliberal rentista da globalização, ou haverá um agravamento da perversa concentração de renda em curso nos países ocidentais? Aprenderemos outras formas de relações e comportamentos, como nos ensinam muitas nações indígenas e outros povos da América Latina e alhures, a exemplo das mulheres estudadas por Federici com suas práticas coletivas, comunitárias de resistência, ou continuaremos nesta escalada do individualismo que, conforme afirmava Louis Dumont no século passado, é a ideologia diferenciadora que marca as sociedades ocidentais (agora aprofundada pelos avanços das tecnologias digitais)?

Não podemos prever, mas dimensionar, no presente, que os impactos da pandemia na economia mundial, no mundo do trabalho, nos padrões de sociabilidade, na dinâmica das famílias e nos modos de viver a vida são brutais (Heilborn, Peixoto, \& Barros, 2020). Vivemos uma catástrofe, segundo Verztman e RomãoDias (2020, p. 273), uma mudança abrupta de cena, que

Tende a achatar e a estreitar o que imaginávamos ser a individualidade e a descontinuidade entre os sujeitos. Modos estáveis de vida e de relação, hierarquias sociais e configurações políticas ten- dem a ser profundamente abaladas e transformadas pela catástrofe. Ela faz nascer, de uma hora para outra, diante de nossa pobre percepção, um universo novo dentro do qual temos dificuldade para nos reconhecer. Lugares antes bem definidos tendem a perder sua nitidez. Indo mais adiante em nossa caracterização, sugerimos que a catástrofe nos faz também reviver experiências subjetivas precoces nas quais grandes zonas de indiferenciação para com o mundo definiam nosso modo de viver. Os aspectos elencados acima nos parecem suficientes para supor que situações de catástrofe favoreçam certas experiências coletivas de dor, sofrimento ou desalento.

Enquanto evento que deixa suas marcas em todos que por ela passam, a pandemia tem necessariamente um caráter coletivo. A colisão fragmentou a vida ordenada expondo fragilidades quanto à saúde pública e à proteção social no mundo inteiro. Deu visibilidade às desigualdades e à complexa trama de produção de um amplo contingente de vulneráveis em nível planetário. Entretanto, não podemos desconsiderar as particularidades do cenário nacional, no qual os enfrentamentos operados pelos brasileiros ganham tonalidades e contornos distintos de outros lugares do mundo. A passagem por essa catástrofe, apesar de ser um evento de proporções mundiais, não se expressa de modo homogêneo entre os sujeitos e populações. Nesse novo universo em que temos dificuldade de nos reconhecer, os cenários de vida vão incidir diretamente nas experiências de sofrimento, vão favorecer ou não a elaboração de formas de enfrentamento, individuais e coletivas, para lidar com o imponderável do desamparo, com o esvaziamento subjetivo e com os efeitos das políticas de abandono e morte que submetem parcelas vulneráveis da população a violentas catástrofes cotidianas - agora escancaradas.

Seremos capazes de retirarmos as máscaras teatralizantes das imagens-fluxo do mercado para assumirmos que o mundo comum já estava em ruínas antes da chegada da Covid-19? Abraçaremos esse destino que se pôs a desmoronar territórios existenciais bem edificados, mas não menos mortíferos, para forjar formas de expansão da vida em práticas coletivas e comunitárias de resistência? Ou continuaremos mortificados, oferecendo nossos corpos e próteses identitárias à escalada negacionista do individualismo egocêntrico? Saberemos contrapor pastores e mitos para 
reterritorializar nossos passos nos desertos de sentido trazidos pela pandemia? Acolheremos o desamparo desde uma posição trágico-utópica para potencializar outros mundos?

\section{Saúde mental, iniquidades sociais e fascismo viral ${ }^{8}$}

\section{Na morte, o futuro é colapsado no presente.}

(Mbembe)

A pandemia da Covid-19 chegou até nós em meio a uma outra catástrofe de caráter político e social. O mundo inteiro tem testemunhado o desastre político-institucional e a fragilidade democrática em que vive o Brasil. Passamos pelo golpe da presidenta Dilma Rousseff em 2016, por eleições fraudulentas em 2018 baseadas em fake news, até chegar à calamidade ético-política que é o governo Bolsonaro, com seus matizes fascistas, racistas, sexistas e antidemocráticos. Nessa catástrofe política, uma das estratégias governamentais mais perversas que tem sido utilizada, para além da negligência em relação à vida e morte das pessoas, que nos coloca na segunda posição em número de mortes em nível mundial, é a aceleração de medidas contra os direitos de cidadania, contra o meio ambiente, contra o patrimônio público, material e imaterial, desse país.

Essa situação de fragilidade democrática, de perdas de direitos, de desproteção por parte das instituições que deveriam nos proteger e fazer com que a pandemia fosse enfrentada de maneira competente e responsável, tudo isso tem sido um forte disparador de sofrimento, servindo para ampliar os gradientes de vulnerabilização da população. Se as produções subjetivas na atualidade já são marcadas pelo individualismo, pela lógica do consumo, pelo enfraquecimento do sentido de comunidade, pelo declínio de valores coletivos, pela intolerância à diversidade e por uma disposição subjetiva favorável à violência, a irrupção da pandemia no Brasil agrega outros elementos como o descaso (deixar viver na precariedade) e a afirmação do extermínio de indesejáveis. Fica claro que estamos, como dizem Wolff et al. (2020, p. 2) em um estado de exceção, no qual “o genocídio dos corpos racializados, vítimas contumazes do capitalismo e da necroeconomia neoliberal" é uma de suas facetas.

Assim, a relação entre tais políticas de morte (Mbembe, 2016) e a intensificação do sofrimento psíquico dos brasileiros na pandemia é um aspecto de singularidade que nos toca e um dos efeitos produzidos pela atual conjuntura política do país. A perda das referências que norteavam a nossa vida cotidiana, instigada pela pandemia, ocorre em um momento de insegurança institucional e democrática, a qual se converte em alimento para capturas micropolíticas (subjetividades) e de adesão à racionalidade governamental necroliberal, ecoando nos desejos de liberdade de expressão, mesmo ao se tratar de valores indefensáveis e antidemocráticos; de gestão da própria vida, mesmo se isso implicar contaminar-se pela Covid-19 voluntariamente; e de autonomia, mesmo se repercutir na vida coletiva como a transmissão do vírus causada pela não adesão às medidas de proteção e o consequente esgotamento dos sistemas de saúde provocado pelo aumento dos casos de contaminação e de internação hospitalar.

Esses enunciados virulentos e mortíferos, formatados antes mesmo da pandemia, geram performances um tanto quanto bizarras e nos colocam em um estado de alerta constante que nos leva à exaustão, e se superpõem, sem sombra de dúvida, à energia que poderia ser dispendida na criação de estratégias coletivas e menos solitárias para a gestão dessa crise humanitária pela qual estamos passando. Um dos aspectos que tem chamado atenção diz respeito à relação das pessoas com a cidade e com os espaços públicos. Paradoxalmente, tem havido uma supervalorização dos espaços privados, apesar do desejo manifesto e generalizado de voltar às ruas. Observa-se um temor em voltar a ocupar o espaço público - sinônimo de insegurança - e a produção de mecanismos de autossegregação e isolamento, que ganham status de distinção social e civilidade.

No Brasil, a concentração de alguns grupos em espaços específicos do território urbano e a constituição de grandes áreas relativamente homogêneas, associada ao perfil socioeconômico e ao capital cultural, configuram "uma "geografia de oportunidades" que penaliza os moradores de determinadas áreas" (Carvalho, 2020, p. 140). Diante disso, é necessário atenção para que o isolamento social, devido à

\footnotetext{
${ }^{8}$ Expressão utilizada por Duarte (2009) para referir-se à modalidade de contaminação endêmica e disseminação da lógica biopolítica na atualidade, fundada na preservação da vida de uns e na aniquilação da vida de outros.
} 
pandemia, não intensifique mais ainda o confinamento das nossas vidas cotidianas - padrão de sociabilidade já tão naturalizado na contemporaneidade-, nem desmonte nossos esforços no sentido de democratização do uso do espaço público, de redução das desigualdades e da segregação socioespacial no país.

No entanto, é preciso destacar um aspecto: o impacto da pandemia na vida das pessoas, na produção de sofrimento psíquico, na busca por referências e ancoragem, por uma "reconstituição mínima da localização subjetiva no mundo" (Verztman \& Romão-Dias, 2020, p. 275), é muito diverso e desigual. Aparentemente, não há diferença de classe, raça e sexo no que se refere ao contágio, mas a igualdade frente ao vírus é uma ficção, já que há desigualdades gritantes no que tange às formas de exposição e de adoecimento. No Brasil, uma série de intervenções cirurgicamente produzidas jogam determinados grupos sociais, tais como os povos tradicionais, os moradores de rua, a população LGBTI, dentre outros, em zonas de menor visibilidade e de desproteção social. Com base em Santos (2020), Wolff et al. (2020, p. 1) destacam que

. . . alguns grupos sociais são mais suscetíveis em razão de suas condições socioeconômicas e da falta de políticas públicas adequadas, visibilizando os que estão "ao sul da quarentena": mulheres, trabalhadoras e trabalhadores precários ou informais, moradoras e moradores de rua, de periferias pobres e de favelas, as/os internadas/os em campos de refugiados e prisões, idosas/os, deficientes físicos.

As estatísticas, em nível mundial, têm mostrado que a população mais pobre e as minorias étnicas, de forma geral, têm sido as mais afetadas e vítimas mortais, o que está associado diretamente às precárias condições de vida e renda, à dependência do transporte coletivo e do sistema público de saúde, que por sua vez, não está distribuído, nem ofertado equitativamente, à existência de doenças prévias e comorbidades que exigem continuidade de cuidados que não é oferecida, à moradia nas periferias pobres, ao trabalho precário e informal, aos arranjos familiares com forte presença de avós como cuidadoras, facilitando a transmissão intrafamiliar e de idosos.

Não por acaso, a população negra representa um grande contingente no índice dos afetados pela Covid-19; tampouco é por acaso que os dados sobre a saúde da população indígena nessa pandemia sejam absolutamente desconhecidos e negligenciados; que a desproteção e os casos de morte de moradores de rua e da população LGBTI tenha se ampliado nesse cenário; que os trabalhadores informais como entregadores, trabalhadoras domésticas e os cuidadores de pessoas idosas representem um percentual importante, mas subnotificado, dos casos de contágio e morte; que danos secundários provocados pelo confinamento, como o aumento do registro de feminicídios e de violência doméstica, que afeta diretamente as mulheres e crianças nesses tempos de confinamento, é observado em cenários de maior vulnerabilidade e de tensões provocadas pelas perdas econômicas, restrições de circulação e de acesso ao sistema de proteção. Sem esquecer o caráter androcêntrico das políticas das instituições financeiras internacionais frente aos efeitos devastadores da Covid-19 no cotidiano das mulheres, principalmente as latino-americanas, políticas que tradicionalmente desconsideram as desigualdades de gênero quanto à pesada carga do trabalho doméstico e dos cuidados (Bohoslavsky \& Rulli, 2020).

Essas situações evidenciam os marcadores sociais da diferença, os grupos mais vulneráveis e refletem as invisibilidades, desigualdades e interseccionalidades entre classe social, raça/etnia, geração e gênero no que se refere à pandemia e seu manejo. Deslocam o discurso homogeneizador da pandemia como fenômeno meramente biológico. Tal realidade tem sido amplamente problematizada em âmbito mundial. As interfaces entre pandemia, desigualdades sociais, diferenças demográficas e populações vulneráveis ocupam o centro do debate atual, já que os condicionantes sociais assumem importante papel no perfil de morbimortalidade de cada país e região.

Carrara (2020), ao relembrar a importância das ciências humanas e sociais na saúde pública e no cenário de crise sanitária e política como a que vivemos no Brasil, traz contribuições fundamentais da área, que a partir da crítica sistemática à cosmovisão individualista, sustenta a ideia de que os indivíduos não são equivalentes uns aos outros; que o modelo epidemiológico clássico não considera as singularidades e as diferenças que remetem a marcadores sociais como raça, classe, gênero, geração sexualidade; e que os indivíduos não se movimentam em "uma espécie de branca planície, uma superfície plana, lisa e homogênea" (Carrara, 2020, p. 3), ao se referir ao espaço social por onde as pessoas circulam e vivem. 
Ortega e Behague (2020), ao refletirem sobre modelos globais de saúde, alertam para a ineficiência do "modelo de "tamanho único", de aplicabilidade global, ou seja, "de medidas sanitárias e modelos epidemiológicos com pouca ou nenhuma consideração dos diferentes contextos locais; que não levam em consideração as condições de vida e outras características das comunidades para as quais se destinam" (Ortega \& Behague, 2020, p. 3). Ressaltam que

intervenções que são efetivas em determinado local não são necessariamente traduzíveis para outros locais; mas quando são, são necessários um conhecimento íntimo e uma resposta sensível às diferenças entre os contextos, o que é muito diferente de apelos que generalizam modelos de “tamanho único” (Ortega \& Behague, 2020, p. 5).

Em abril de 2020, o Ministério da Saúde do Brasil e a Organização Pan-Americana da Saúde (2020) deram início a uma campanha para promover a saúde mental no contexto da Covid-19, alertando para o sofrimento causado pelas restrições de contato social, pela perda de familiares, pelo medo do contágio e adoecimento e, consequentemente, para os riscos de aumento de depressão, de consumo abusivo de álcool e outras drogas e de eclosão de crises psiquiátricas. Em relação às pessoas com diagnóstico de esquizofrenia, evidenciam a possibilidade de haver maior dificuldade em adotar medidas de higiene e de menor adesão medicamentosa e terapêutica, especialmente, diante do fechamento de serviços de atenção psicossocial e interrupção do atendimento presencial. Em função disso, essas instituições de saúde divulgaram uma série de recomendações e orientações para a população em geral, para profissionais de saúde, bem como para gestores e coordenadores. Outras produções nesse sentido também foram publicadas (Melo et al., 2020; Faro et al., 2020; Schmidt, Crepaldi, Bolze, Neiva-Silva, \& Demenech, 2020; Zwielewski et al., 2020).

Apesar da importância de tais iniciativas, no que tange à saúde mental, é fundamental não perder de vista as especificidades dos diferentes grupos sociais, das condições de vida, o risco da uniformização cultural e da padronização de procedimentos. Além disso, de uma leitura asséptica e descolada da atual conjuntura sócio-política. Ao desconsiderar as particularidades da situação brasileira na abordagem dos impactos subjetivos vividos pela população, com ou sem pandemia, reforça-se a hegemonia das forças despolitizadoras e psicologizantes, com intuito de uniformizar e de generalizar a experiência de sofrimento. Infelizmente, é o que temos observado na maior parte das produções acadêmicas e profissionais no campo da psicologia, cuja abordagem quanto à saúde mental e à oferta de serviços de atenção nessa pandemia parecem se adequar a qualquer indivíduo, de qualquer parte do planeta. Afinal, a pandemia é um fenômeno "natural" e a resposta psicológica diante disso segue um padrão "universal".

Em contraposição a isso, observa-se a profusão da produção científica destacando os efeitos da pandemia na saúde mental de diferentes grupos e em contextos sociais, dentre os quais situam-se migrantes, população em privação de liberdade, portadores de doenças crônicas e pessoas com histórico de sofrimento psíquico (Pires, 2020; Lima et al., 2020; Garrido \& Rodrigues, 2020). Essa produção representa uma iniciativa de romper com o "silenciamento da cultura" na política e nos serviços de saúde mental, indicado por Ortega e Wenceslau (2019, p. 58), no que se refere à ausência das causas sociais e econômicas, das variadas concepções e crenças associadas à saúde mental e às formas de tratamento e cura produzidas em um país multicultural como o Brasil.

No entanto, o repertório de respostas produzidas no âmbito da saúde mental em meio à pandemia, especificamente pelas equipes vinculadas à Rede de Atenção Psicossocial (RAPS), ainda é pouco conhecido. Em 18 de maio de 2020, o Conselho Nacional de Saúde (CNS) recomendou a revisão da nota técnica emitida pelo Ministério da Saúde sobre medidas de proteção contra a Covid-19 e a inclusão da RAPS nos planos de contingência dos estados e dos municípios. O CNS pediu atenção às especificidades da Atenção Psicossocial, a revisão das medidas de proteção nos serviços da RAPS, a criação de estratégias de seguimento do cuidado e manutenção dos vínculos, de acompanhamento dos casos crônicos e atenção às condições de vulnerabilidade, dentre outras recomendações. A efetivação e alcance dessas medidas ainda são desconhecidas (Conselho Nacional de Saúde, 2020).

Nesse sentido, compartilhamos uma experiência de Educação Permanente em Saúde em curso de um município nordestino, junto aos trabalhadores da APS e RAPS, dando visibilidade aos enfrentamentos operados em relação à lógica de despotencialização dos coletivos e à busca de restituição da "normalidade". 


\section{Da impotência às possibilidades: reinvenção da vida no cenário da RAPS}

\author{
Por que vocês não sabem do lixo ocidental? \\ não precisam mais temer, \\ não precisam da solidão, \\ Todo dia é dia de viver.
}

(Fernando Brant, Marcio Borges e Lo Borges)

A capacidade de resposta da Política Nacional de Saúde Mental (PNSM) à pandemia da Covid-19 não pode ser desatrelada do desmantelamento geral das políticas públicas em processo no país, políticas que foram duramente conquistadas nos últimos 30 anos. A PNSM é uma delas. O projeto político de Reforma Psiquiátrica vem gradativamente perdendo força na última década. Isso se agravou desde o golpe de 2016, quando setores mais conservadores ocuparam o Ministério da Saúde e a Coordenação Nacional de Saúde Mental, com a forte presença da Associação Brasileira de Psiquiatria, que sempre foi claramente contra a reforma psiquiátrica. Desde então, temos assistido a sucessivas manobras para enfraquecer o processo de reforma psiquiátrica no país e para desmontar a Rede de Atenção Psicossocial (RAPS), de acordo com a lógica conservadora e privatista que prevalece no país.

Assim, poucos serviços de atenção psicossocial foram autorizados pelo Ministério da Saúde nos últimos anos; as taxas de acessibilidade e cobertura estão piorando no território nacional; existem grandes vazios assistenciais em todas as regiões do país; grande parte dos recursos públicos tem sido desviada para hospitais psiquiátricos e para a abertura e manutenção de comunidades terapêuticas. O modelo territorial e comunitário está enfraquecido, gerando a extinção de muitas equipes de Atenção Primária à Saúde (APS), dentre elas os NASFs, no território nacional. Em outras palavras, vivemos um quadro preocupante de retrocessos no qual a PNSM não tem se firmado como política de Estado, mas flutuado ao sabor dos governos; o avanço da lógica asilar, centrada no hospital, é visível; a retração dos serviços da RAPS também é evidente; a expansão das necessidades de saúde mental e os gradientes de vulnerabilidade associados às desigualdades sociais e às questões de gênero, raça e sexualidade têm aprofundado a falta de cobertura e de respostas adequadas do setor.

Considerando esse processo de progressivo desmonte que tem afetado os ânimos dos trabalhadores da RAPS, as respostas insuficientes ou inexistentes dos governos para minimizar os danos psicossociais decorrentes da vivência da pandemia e do aprofundamento da crise econômica, muitos são os receios e preocupações quanto aos cenários, presentes e futuros, para a saúde mental. Lidar com uma situação pandêmica, cuja melhor estratégia de prevenção é o distanciamento social, demanda uma gestão interinstitucional e interfederativa competente, que favorece a participação comunitária e investe na aliança entre direitos e cuidados - o que não temos observado no Brasil.

Estima-se que entre um terço e metade da população poderá desenvolver transtornos mentais, caso não haja a oferta dos cuidados sócio comunitários e a quantidade de profissionais necessários (Fundação Oswaldo Cruz, 2020). Junto a isto, há o risco do incremento da patologização e medicalização do sofrimento, que já era uma realidade nas práticas de saúde brasileiras antes da pandemia, potencializando danos à saúde mental. Nesse sentido, podemos assistir ao colapso do sistema de saúde não apenas nos serviços destinados à atenção à Covid-19 - como temos infelizmente observado -, mas, a médio prazo, nos serviços da RAPS. Além disso, velhas práticas manicomiais têm sido observadas, tais como a não transferência de usuários internados em hospitais psiquiátricos, em manicômios judiciários, no sistema socioeducativo e em outras unidades asilares ou prisionais para os hospitais gerais, quando confirmadas as suspeitas de infecção por Covid-19.

É preciso, portanto, alertar que os diferentes modos de gestão da crise sanitária, socioeconômica e política trazem diferentes repercussões para a saúde mental. Dessa forma, os gestores de saúde precisam estar atentos à necessidade de ampliar os dispositivos de apoio e preparar suas equipes por meio de espaços de educação permanente em saúde e do fornecimento de condições de biossegurança no trabalho para acolher a demanda advinda do contexto pandêmico. É imprescindível subsidiar as equipes para atuarem com foco na articulação entre proteção social, promoção de equidade e cuidado em saúde, assim como para o fortalecimento das redes intersetoriais e sanitárias, das redes de apoio socioafetivas e das estratégias de cuidado sociocomunitárias, coletivas e entre pares. Da mesma maneira, é preciso garantir as condições para a identificação precoce, encaminhamento e tratamento dos casos agravados, em especial quanto à violência, ao risco de suicídio e ao abuso de álcool e outras drogas. 
Contudo, como fazê-lo em um contexto de desmonte e desinvestimento? Como operá-lo em um cenário em que os próprios trabalhadores estão submetidos à intensidade dos riscos e atravessados pela angústia e pelo sofrimento social que advém da vivência de uma pandemia em tempos de necropolítica? Como mobilizar os desejos dos trabalhadores quando a experiência do desamparo e o esvaziamento dos sentidos se interpõem e os atravessam? Tendo em conta as problemáticas e questões aqui levantadas, algumas experiências de apoio e educação permanente em saúde com profissionais da Rede de Atenção Psicossocial e da Atenção Primária em Saúde de municípios do Rio Grande do Norte estão sendo realizadas por meio de ações de extensão e parcerias interinstitucionais entre o Departamento de Psicologia da Universidade Federal do Rio Grande do Norte, a Secretaria Municipal de Saúde de Natal e a Secretaria Estadual de Saúde Pública do RN. Nosso intuito neste texto é compartilhar essa experiência, destacando aquilo que, na nossa compreensão, vem desacomodando e interrogando as equipes, seja em termos dos modos de cuidado na RAPS, seja dos modos estabelecidos de vida.

Vale lembrar que os trabalhadores das políticas públicas de saúde foram os primeiros convocados a encarar a violenta virulência da pandemia e agir diante desse corpo estranho em rota de colisão com o mundo, para o qual ainda não há vacina nem tratamento comprovadamente eficaz. Aliás, são as mulheres - trata-se, não esqueçamos, de um campo ocupado majoritariamente por elas - que são diretamente exigidas a reposicionar seus saberes, agires e devires, e encarar uma realidade em choque com o instituído'. Porém, sustentar subjetiva e tecnicamente o cuidado nesses cenários da pandemia, em que a emergência e a angústia não afetam apenas a pessoa atendida, mas também o próprio profissional, é um desafio sem precedentes. Nas palavras de uma médica, trabalhadora da RAPS de Natal, para sobreviver a esse momento de emergência é preciso "primeiro ajustar a máscara de oxigênio em si mesmo e depois ajudar o outro a colocá-la".

Sabe-se, sobretudo, quando as condições de biossegurança não estão garantidas, como temos visto no Brasil, os problemas de saúde mental relacionados ao trabalho em saúde aumentam significativamente. Assim, acolher a convocação ética e política de reinvenção coletiva do cuidado em defesa da vida, fazendo frente à angústia que nos atravessa, envolve a compreensão de que nenhum trabalhador de saúde pode sustentar sozinho o lugar do cuidar. Ao contrário, é por meio do trabalho em equipe e em rede, articulando linhas de cuidado a partir das especificidades das necessidades de saúde dos territórios e das demandas singulares, que a atenção integral se torna possível, ao passo que se protege a própria saúde dos trabalhadores e se delineiam itinerários terapêuticos de corresponsabilização e coprodução de saberes e de saúde.

As experiências de apoio e de educação permanente em saúde com profissionais da Rede de Atenção Psicossocial e da Atenção Primária em Saúde são constituídas de espaços e encontros abertos, na modalidade remota, com vistas à produção de laços entre os trabalhadores e equipes para o compartilhamento de experiências vividas nos contornos da pandemia. Têm ocorrido quinzenalmente, desde maio, com adesão expressiva dos trabalhadores, tendo iniciado com a rede de Natal e se ampliado para a participação de profissionais dos outros municípios potiguares, por solicitação dos próprios participantes. As narrativas de vivências do contexto pandêmico, dentro e fora dos serviços, são a substância sobre a qual se processa o endereçamento ao grupo, a escuta do outro, o acolhimento das questões e a construção de saberes e estratégias. Esse trabalho coletivo de encontro, narrativa, produção de comum ${ }^{10}$ (Teixeira, 2015) e construção de projeto compartilhado tem possibilitado invenções que atualizam a função da RAPS em um momento em que, mais do que nunca, é importante potencializar

\footnotetext{
${ }^{9}$ Aqui nos referimos ao campo conceitual do Institucionalismo (Baremblitt, 2002), que situa nas teias das instituições a sede/substância da reprodução de lógicas normativas que sustentam os processos sociais de produção de sujeitos e modos de vida. Nessas lógicas, o instituído é aquilo que, uma vez institucionalizado, opera forças para sua perpetuação e resiste aos processos instituintes, os quais irrompem para agenciar mudanças. A pandemia de Covid-19 se apresenta como um acontecimento com potência para interrogar as forças do instituído, ao escrachar uma realidade perversa, ao dar a ver as vísceras dos processos pelos quais, nas instituições - saúde, comunicação social, educação, linguagem, direito, entre outras - se naturalizam os efeitos nefastos das práticas privatistas e medicalizantes de saúde, que não protegem vidas, ao contrário, atuam a serviço do lucro e banalizam o sofrimento e as mortes, em especial, da parcela mais vulnerabilizada da população.

${ }^{10}$ Teixeira (2015) se remete a Antônio Negri para pensar a produção do comum como imanente à organização do trabalho contemporâneo, destacando sua centralidade para o trabalho em saúde. Nos termos colocados pelo autor, a produção do comum pode ser pensada na perspectiva da ética de Spinoza, referindo-se à arte de fazer composições, fazer comunidade, nos encontros entre diferentes corpos, gerando potência de vida.
} 
laços de cuidado e modos mais solidários de viver, contra a lógica que reforça vulnerabilidades.

Quando dizemos “atualizam", se trata de sublinhar que algo se inventa a partir do que já existe, mas também do que está em potência, conforme nos ensina Deleuze (1991) sobre o plano do virtual ${ }^{11}$. Uma invenção faz furo em uma superfície de sentidos instituídos, produz abalos nos ritmos já incorporados, desenha novas formas com o movimento das linhas que tecem a experiência coletiva, dando contornos e relevos inéditos para os territórios de existência. Foi com intuito de pensar o que é preciso furar, quais estruturas movimentar, que outros ritmos pautar, quais novas formas e contornos o cuidado na RAPS pode tomar, a partir dos abalos trazidos pela pandemia, que iniciamos esse espaço para o compartilhamento e a problematização dos modos de organização, de concepção e de operação do trabalho em saúde mental.

Partimos do princípio que qualquer transformação no campo dos saberes e das práticas em saúde só pode ser pensada como efeito de dispositivos que agenciem novos modos de pensar-experimentar o trabalho, que chamaríamos, como a personagem Justine, de trágico-utópicos, o que inclui também fazer entrar em cena a própria saúde mental como tecida na imanência entre trabalho e vida. A partir dessa perspectiva, a invenção de outros modos de se conduzir nos territórios do cuidado em tempos de pandemia está intimamente relacionada a uma ruptura com os modos de subjetivação pelo trabalho que reduzem o trabalhador a operador de uma técnica que parece garantir caminhos seguros, mas que, descontextualizada da cena do cuidado, não faz outra coisa senão mascarar e burocratizar os fluxos singulares da vida.

Nessa direção, nos propomos a discutir aspectos que vêm emergindo nos espaços de apoio (EPS), destacando algumas linhas de problematização ético-políticas em torno das técnicas, mas, sobretudo, para além delas. Uma primeira linha diz respeito à vivência de precarização do trabalho e desinvestimento das instâncias de gestão, nos seus diversos níveis, nas políticas públicas de saúde, experimentada pelos trabalhadores como algo que incrementa o cansaço e a desesperança, despotencializando os caminhos da reinvenção do trabalho. Nas palavras de um dos profissionais: "esse momento tem sido um desafio, põe em questão vários problemas que enfrentávamos antes do isolamento social".

Emergem nas narrativas dos participantes realidades antigas que seguem pedindo transformação. Serviços sediados em locais com problemas estruturais nas edificações, distantes ou que compartilham o espaço com outras equipes e serviços de saúde, sem acesso à internet e computador; a mudança de sede de um Centro de Convivência e Cultura (CECCO) de um bairro histórico e central da cidade para dar lugar à ampliação de um pronto atendimento em curso, já antes da chegada da Covid-19 e potencializada por ela, mobiliza e angustia usuários e profissionais; a suspensão do rodízio da presencialidade dos profissionais nos CAPS, sentida como repentina, precoce e descuidada para com a saúde dos trabalhadores; o não fornecimento da estrutura necessária para o trabalho remoto, que viabilize a comunicação com os usuários por telefone ou internet e que faz com que alguns profissionais comprem ou cogitem comprar um chip novo para manter, ao mesmo tempo, o trabalho no domicílio e o vínculo com os usuários; o profissional que media o grupo terapêutico - agora suspenso - e faz contato com os participantes com seu próprio aparelho celular, pois não há telefone no CAPS; a equipe reduzida e os atendimentos psiquiátricos suspensos porque o psiquiatra é do grupo de risco. Infindável seria essa lista se nos propuséssemos a continuar a registrá-la.

Uma segunda linha que parece tecer as narrativas dos encontros de EPS se refere ao atravessamento da vivência da pandemia no próprio corpo, o medo de perder familiares e amigos, a ameaça da própria morte, a tristeza com a incomensurabilidade das perdas humanas em curso e os impasses éticos decorrentes dessa convocação de estar no front das estratégias de intervenção em saúde na pandemia e, ao mesmo tempo, proteger-se do contágio. Um sonho/pesadelo sobre estar em um ônibus lotado com pessoas de máscara, mas muitas com os rostos nus, que assombram e tiram o sono de uma das participantes, é compartilhado nas conversas que antecedem o início da atividade proposta para o dia, intitulada "Acolhimento em tempos de pandemia". Narrativa que convida à contação de outro sonho, em que a moderadora do espaço

\footnotetext{
${ }^{11}$ Atualizar, aqui, toma o sentido apontado por Deleuze (1991) quando o autor diferencia a atualização de virtualidades da realização de possibilidades, propondo que a primeira implica um processo de diferenciação, que traz para o real o absolutamente novo, que não estava contido no conjunto de possíveis pré-formatados ou pré-existentes, a partir de um todo aberto que ele chama, como Bergson, de virtual.
} 
se vê atravessada pela angústia de não poder tocar em uma criança que está em perigo, o que a remete à escuta dos profissionais do CAPSi no encontro anterior, em que compartilharam suas preocupações com as crianças em sofrimento psíquico grave que "perderam tão de repente o vínculo com o espaço da escola e do CAPS", ponderando a insuficiência da escuta dos pais ao telefone e, ao mesmo tempo, falando sobre efeitos de apoio contidos nesse gesto de ir na direção do outro.

Uma profissional do NASF compartilhou sua sensação de trabalhar $24 \mathrm{~h}$ sem descanso, pois quando não está cuidando dos usuários na unidade de saúde em que participa do acolhimento dos sintomáticos da Covid-19, está às voltas com as vivências de ansiedade dos familiares, alguns com transtornos mentais diagnosticados antes da pandemia e que se agudizaram a partir dela. Outra profissional refere a angústia de não poder realizar os grupos na Unidade de Saúde da Família, incrementada pela dificuldade de contactar os participantes do grupo de adolescentes vulneráveis, com histórico de violência, tentativas de suicídio e que estavam bastante vinculados aos espaços grupais da unidade, ao mesmo tempo em que se vê tomada pelo medo de que os grupos voltem a acontecer em um futuro próximo, colocando todos em risco. Atendimentos de urgência em saúde mental feitos de forma presencial, com "paramentação completa", conta inquieto outro participante do espaço de EPS, ao descrever a cena em que se sente estranho acolhendo, com o rosto coberto, uma usuária em crise que lhe toca profundamente ao pedir-lhe para retirar a máscara.

O pedido de apoio à universidade e de subsídios técnicos parece ser outra linha narrativa que compõe os encontros virtuais em andamento, derivando questões sobre a função da RAPS nesse momento e como operar o cuidado em um cenário de desterritorialização das práticas. $\mathrm{O}$ manejo da ansiedade, o acolhimento em tempos de distanciamento social e a gestão de redes de cuidado na pandemia foram as temáticas identificadas pelo grupo, até o momento, para serem discutidas, as quais surgiram de um processo autoanalítico e autogestivo de identificação de demandas e construção coletiva de um projeto refeito a cada encontro.

A ansiedade foi situada como afeto com um amplo e polissêmico espectro de relações, atribuído, simultaneamente, à incerteza quanto ao futuro, à falta de confiança nas orientações oficiais das autoridades sanitárias, ao momento político-econômico do país, à impotência provocada pela situação de não poder cuidar do outro devido ao isolamento social ou de não ter como participar das decisões de gestão da saúde frequentemente consideradas eleitoreiras -, ao medo de profissionais e usuários em contrair o vírus e contaminar a família, à precariedade das condições de vida da população que leva à dificuldade de cumprir o distanciamento social, à expectativa pelo resultado dos testes, à espera dos usuários por leitos em UTI, às mortes já ocorridas, às que virão. O "peso da impotência", como refere uma das participantes, parece ser a tônica que marca os sentidos e as cenas associados à vivência da ansiedade nas narrativas tecidas coletivamente no espaço-tempo do grupo.

Quando o acolhimento entrou na roda na sequência da discussão sobre a ansiedade, os afetos e a desterritorialização dos lugares próprios e dos outros, parece ter se produzido um certo giro narrativo: da impotência às possibilidades. Em torno da pergunta de uma das participantes: "Como a rede de atenção psicossocial pode estar se reinventando para continuar acolhendo?", movimentos de deslocamento da impotência para a ação foram se anunciando, ainda que timidamente e acompanhados de relatos de sensações de insuficiência e dúvida. Em um CAPS AD, os servidores criaram a "caixa do anjo", por meio da qual trocam mensagens entre si, propondo "otimismo, atenção e cuidado"; a caixa é aberta diariamente e os recados distribuídos aos destinatários. Uma carta aos usuários também foi elaborada pela equipe, com uma linguagem que "provoca o usuário a pensar no autocuidado e na relação serviço-usuário-profissional sem moralismos", convidando a aprender juntos como se cuidar na pandemia.

No CAPSi, dentre outras ações, a equipe decidiu montar kits de higiene básica para disponibilizar às famílias mais vulneráveis vinculadas ao serviço; na mesma direção, para intervir na concretude do cotidiano que sustenta a vida, em suas várias dimensões, também construíram uma biblioteca, de modo que as crianças podem retirar os livros e trocar sempre que quiserem, levando um pedaço do CAPSi consigo para casa. No CECCO, o Instagram e o grupo de Whatsapp têm sido ferramentas potentes de convivência, de encontro, de trocas; criou-se a Rádio Bilola, as oficinas estão acontecendo virtualmente e até o Arraial de São João se transportou para os territórios virtuais, não sem perdas e rupturas, mas como movimento de resistência de um serviço que tem se sustentado dessa força coletiva, desde seus começos. Dessas invenções em gérmen, destaca-se o compartilhamento sobre como os 
marcadores culturais de cada território são importantes para a reinvenção do acolhimento, dando contornos aos afetos e tramando redes de cuidado socioafetivas.

A rede de cuidado e os entraves em termos de gestão são também linhas que transversalizam as narrativas e diálogos produzidos no dispositivo dos encontros virtuais da RAPS potiguar. Uma das participantes refere que "a procura no CAPS é diária, antes e depois da chegada da pandemia" e que um dos maiores impasses que experimenta em seu trabalho, diante do sofrimento de alguém que precisa de ajuda, é não contar com outros pontos da rede para encaminhar o usuário quando identifica que não se trata de uma demanda para o CAPS. Para ela, "o acolhimento é muito importante, pois pode gerar uma melhora no usuário ou pode ser um dano para a pessoa que procura o serviço". Fica, então, com a questão: "para onde mandar essa pessoa", se a atenção básica tem tantas dificuldades? Como garantir que o usuário será "bem acolhido" em outro serviço da rede?

No compartilhamento dessas perguntas e inquietações, a curiosidade e o interesse dos participantes se movem na direção de saber como está o trabalho do outro - serviço ou profissional - no atual contexto. Esse interesse se incrementa no coletivo a cada encontro e vai dando consistência à demanda de articulação de ações em rede, de construção de estratégias coletivas para o cuidado na RAPS e de sustentação das práticas da atenção psicossocial em tempos de pandemia, em uma espécie de plataforma-mosaico de aprendizagens mútuas e permanentes. Nessa direção, refere uma participante: "eu tenho me sentindo solitária em relação aos outros colegas da rede municipal" $\mathrm{e}$ acrescenta que entende os encontros virtuais, nesse momento, como uma proposta para fortalecer a rede, sugerindo que outros profissionais e serviços sejam "encorajados a participar".

A menção à coragem parece ressoar afetos compartilhados, situar um comum, abrir possibilidades de enunciação coletiva. Se a reforma psiquiátrica, desde seus primórdios, sempre foi um movimento contra-hegemônico e de resistência micro e macropolítica, o que dizer do desafio que a ela se impõe nesse momento? "Coragem!", dizem os trabalhadores uns aos outros. Coragem para seguir lendo, enunciando e intervindo no mal-estar gerado pela insistência dos manicômios, ainda que se esteja falando da impotência vivida nas próprias práticas de cuidado para consigo e com o outro. Coragem para interrogar a estrutura social que adoece, silencia, anestesia e mata. Para renunciar ao ideal de adaptação social, que captura a existência em um campo de sentidos instituídos. Para oferecer a possibilidade de pertencimento na diferença, acolhendo também a face intraduzível desta - a Justine em cada um de nós. Para sustentar o cuidado em liberdade, em uma interminável negociação entre direitos e cuidado, especialmente nesse momento, em que as regras e códigos da vida coletiva precisam ser repactuados.

Contudo, afinal, "o que é a liberdade?" - podemos nos perguntar, com Hanna Arendt, Entre o passado e o futuro. Ao criticar a noção de liberdade apartada da política, Arendt desnaturaliza a ideia de que "quanto menor o espaço ocupado pelo político, maior é o domínio deixado à liberdade", na qual se baseou o liberalismo moderno do qual somos herdeiros (Arendt, 2005, p. 195). O que é, então, a liberdade senão esse trabalho ininterrupto - que não diz respeito a uma experiência individual, abstrata, apartada do mundo e fundada em um livre arbítrio - mas que se exerce na ação, com o outro, sobre o mundo para transformá-lo? Assim, a filósofa arranca a liberdade da interioridade individual em que foi aprisionada, para afirmá-la como algo vivido na ação, no espaço público.

É essa dimensão pública do trabalho e do cuidado em saúde mental que parece estar se forjando nos encontros da EPS, permitindo que os problemas, as problematizações e as ações do cuidado em liberdade em tempos de pandemia se sustentem no compartilhamento dos impasses e possibilidades, acolhendo a insuficiência das técnicas, dos protocolos e das normas. As condições da produção do novo no contexto de emergência e crise - e em qualquer outro envolvem colocar em cena os saberes da experiência para fazer surgir a corresponsabilização ética e política pela construção do mundo em que se habita. Assim, nesses espaços remotos experimentais da educação permanente em saúde, não se trata apenas de tomar a experiência singular dos participantes no registro dos conhecimentos instituídos no campo da saúde, mas de acolher o ponto em que desconstroem os saberes $\mathrm{e}$ as práticas vigentes, ao mesmo tempo que criam, com eles, novas possibilidades para agir, nos enlaces do cuidado com o espaço público, a vida coletiva.

Posição anunciada por Justine, no filme de Lars Von Trier, que demanda acolher o acontecimento implacável, o imponderável em curso, o ruir das referências codificadas, para vislumbrar caminhos possíveis em invenções cotidianas. Movimento que implica na apropriação do vivido nos territórios que se redesenham 
com a pandemia, para se lançar em agires sintonizados com as necessidades de saúde e os modos de sofrimento emergentes no agora, e agenciar dispositivos capazes de sustentar as práticas para além das fronteiras-mundo já conhecidas. Dispositivos de abertura e passagens nas encruzilhadas da saúde mental e da democracia, que confrontem a ordem do discurso vigente e suas estruturas de determinação social da saúde, enquanto intervém, de forma solidária e culturalmente sensível, nas micropolíticas cotidianas do cuidado.

\section{Referências}

Arendt, H. (2005). Entre o passado e o futuro (M. W. Barbosa, Trad.). Perspectiva.

Baremblitt, G. (2002). Compêndio de análise institucional e outras correntes: Teoria e prática (5a ed.). Instituto Félix Guattari.

Bohoslavsky, J. P., \& Rulli, M. (2020). Covid-19, instituciones financieras internacionales y continuidad de las políticas androcéntricas en América Latina. Estudos Feministas, 28(2), 1-16. https://doi.org/ 10.1590/1806-9584-2020v28n273510

Carrara, S. (2020). As ciências humanas e sociais entre múltiplas epidemias. Physis: Revista de Saúde Coletiva, 30(2), 1-6. https:// doi.org/10.1590/s0103-73312020300201

Carvalho, I. M. M. (2020). Desigualdades raciais no espaço urbano. Cadernos do CEAS: Revista Crítica de Humanidades, 45(249), 137-166. http://dx.doi.org/10.25247/2447-861X.2020.n249.p137-166

Conselho Nacional de Saúde (2020). Recomendação no 040, de 18 de maio de 2020. http:/ /conselho.saude.gov.br/ recomendacoes-cns/1181-recomendacao-n-040-de-18-de-maio-de-2020

Deleuze, G. (1991). Le Bergsonisme. Paris : PUF.

Duarte, A. (2009). Foucault e as novas figuras da biopolítica: O fascismo contemporâneo. In A. Veiga-Neto, \& M. Rago, Para uma vida não-fascista (pp. 35-50). Belo Horizonte, MG: Autêntica.

Faro, A., Bahiano, M. A., Nakano, T. C., Reis, C., Silva, B. F. P., \&Vitti, L. S. (2020). Covid-19 e saúde mental: A emergência do cuidado. Estudos de Psicologia (Campinas), 37, 1-14. https://doi.org/10.1590/1982-0275202037e200074

Foucault, M. (1996). O anti-Édipo: Uma introdução à vida não-fascista. In P. P. Pelbart \& S. Rolnik (Orgs.), Cadernos de subjetividade. Núcleo de Estudos e Pesquisas da Subjetividade da PUC/SP.

Freud, S. (2010). O mal-estar na civilização, novas conferências introdutórias à psicanálise e outros textos (P. C. Souza, Trad.). Companhia das Letras. (Trabalho original publicado em 1930).

Fundação Oswaldo Cruz. (2020). Cartilha saúde mental e atenção psicossocial na pandemia Covid-19: Recomendações gerais. https://www.fiocruzbrasilia.fiocruz.br/wp-content/uploads/2020/04/Sa\%c3\%bade-Mental-e-Aten\%c3\% a7\%c3\%a3o-Psicossocial-na-Pandemia-Covid-19-recomenda\%c3\%a7\%c3\%b5es-gerais.pdf

Garrido, R. G., \& Rodrigues, R. C. (2020). Restrição de contato social e saúde mental na pandemia: Possíveis impactos das condicionantes sociais. Health and Biological Sciences, 8(1), 1-9. http://dx.doi.org/10.12662/ 2317-3076jhbs.v8i1.3325.p1-9.2020

Han, B. C. (2020, 22 de marzo). La emergencia viral y el mundo de mañana. El País. https://elpais.com/ ideas/2020-03-21/la-emergencia-viral-y-el-mundo-de-manana-byung-chul-han-el-filosofo-surcoreano-quepiensa-desde-berlin.html

Heilborn, M. L. A., Peixoto, C. E., \& Barros, M. M. L. (2020). Tensões familiares em tempos de pandemia e confinamento: Cuidadoras familiares. Physis: Revista de Saúde Coletiva, 30(2), 1-8. http://dx.doi.org/10.1590/ S0103-73312020300206

Lacan, J. (2007). O Seminário, livro 23: O sinthoma (S. Laia, Trad.). Rio de Janeiro, RJ: Zahar. (Trabalho original publicado em 1975-1976)

Lacan, J. (2009). O seminário, livro 1: Os escritos técnicos de Freud (B. Milan, Trad.). Rio de Janeiro, RJ: Zahar. (Trabalho original publicado em 1953-1954)

Lima, S. O., Silva, M. A., Santos, M. L. D., Moura, A. M. M., Sales, L. G. D., Menezes, L. H. S., Nascimento, G. H. B., Oliveira, C. C. C., Reis, F. P., \& Jesus, C. V. F. (2020). Impactos no comportamento e na saúde mental de grupos vulneráveis em época de enfrentamento da infecção Covid-19: Revisão narrativa [Volume especial]. Revista Eletrônica Acervo Saúde, (46), 1-8. https://doi.org/10.25248/reas.e4006.2020 
Mbembe, A. (2016). Necropolítica. Arte \& Ensaios, (32), 123-151. https://www.procomum.org/wp-content/ uploads/2019/04/necropolitica.pdf

Melo, B. D., Pereira, D. R., Serpeloni, F., Kabad, J. F., Souza, M. S., Rabelo, I. V. M., Noal, D. S., Damásio, F., \& Freitas, C. M. D. (2020). Saúde mental e atenção psicossocial na pandemia Covid-19: recomendações para gestores. Fiocruz. https://www.arca.fiocruz.br/handle/icict/41030

Nietzsche, F. (2011). Assim falou Zaratustra: Um livro para todos e para ninguém (P. C. Souza, Trad.). São Paulo, SP: Companhia das Letras.

Organização Pan-Americana da Saúde (2020). Considerações psicossociais e de saúde mental durante o surto de Covid-19. https://iris.paho.org/handle/10665.2/51996

Ortega, F., \& Behague, D. P. (2020). O que a medicina social latino-americana pode contribuir para os debates globais sobre as políticas da Covid-19: Lições do Brasil. Physis: Revista de Saúde Coletiva, 30(2), 1-13. https://doi.org/10.1590/s0103-73312020300205

Ortega, F., \& Wenceslau L. D. (2019). Challenges for implementing a global mental health agenda in Brazil: The "silencing" of culture. Transcultural Psychiatry, 57(1), 57-70. https://doi.org/10.1177/1363461518824433

Paiva, H. (2020). O nascimento de um novo comunismo: Entrevista com Slavoj Zizek. Outras Mídias. https://outraspalavras.net/outrasmidias/zizek-o-nascimento-de-um-novo-comunismo/

Passos, E., \& Barros, R. B. (2009). A cartografia como método de pesquisa-intervenção. In E. Passos, V. Kastrup, \& L. Escóssia (Orgs), Pistas do método da cartografia: Pesquisa-intervenção e produção de subjetividade (pp. 15-31). Porto Alegre, RS: Sulina.

Pires, R. R. C. (2020). Nota técnica ${ }^{\circ}$ 33: Os Efeitos sobre grupos sociais e territórios vulnerabilizados das medidas de enfrentamento à crise sanitária da Covid-19: Propostas para o aperfeiçoamento da ação pública. http://repositorio.ipea.gov.br/bitstream/11058/9839/1/NT_33_Diest_Os\%20Efeitos\%20Sobre\%20Grupos\%20Sociais\%20e\% 20Territ\%c3\%b3rios\%20Vulnerabilizados.pdf

Safatle, V. (2017). Lacan, revolução e liquidação da transferência: A destituição subjetiva como protocolo de emancipação política. Estudos Avançados, 31(91), 211-227. https://www.revistas.usp.br/eav/article/view/141914

Santos, B. S. (2020). A cruel pedagogia do vírus. Coimbra: Almedina.

Schmidt, B., Crepaldi, M. A., Bolze, S. D. A, Neiva-Silva, L., \& Demenech, L. M. (2020). Saúde mental e intervenções psicológicas diante da pandemia do novo coronavírus (Covid-19). Estudos de Psicologia (Campinas), 37, 1-13. https://doi.org/10.1590/1982-0275202037e200063

Teixeira, R. R. (2015). As dimensões da produção do comum e a saúde. Saúde e Sociedade, 24(sup), 27-43. https://doi.org/10.1590/s0104-12902015s01003

Trier, L. V. (Diretor). (2011). Melancolia [Filme]. CinePlayers.

Verztman, J., \& Romão-Dias, D. (2020). Catástrofe, luto e esperança: O trabalho psicanalítico na pandemia de Covid-19. Revista Latinoamericana de Psicopatologia Fundamental, 23(2), 269-290. https://doi.org/10.1590/1415-4714.2020v23n2p269.7

Wolff, C. S., Minella, L. S., Lago, M. C. S, \& Ramos, T. R. O. (2020). Pandemia na necroeconomia neoliberal. Revista Estudos Feministas, 28(2), 1-7. https:// doi.org/10.1590/1806-9584-2020v28n274311

Zwielewski, G., Oltramari, G., Santos, A. R. S., Nicolazzi, E. M. S., Moura, J. A., Schlindwein-Zanini, R, \& Cruz, R. M. (2020). Protocolos para tratamento psicológico em pandemias: As demandas em saúde mental produzidas pela Covid-19. Debates in psychiatry, 1-8. http://www.hu.ufsc.br/setores/neuropsicologia/wp-content/uploads/ sites/25/2015/02/Protocolos-psic-em-pandemias-covid-final.pdf

\section{Magda Dimenstein}

Professora do Programa de Pós-Graduação em Psicologia da Universidade Federal do Rio Grande do Norte, Doutora em Saúde Mental pelo Instituto de Psiquiatria da Universidade Federal do Rio de Janeiro, Rio Grande do Norte - RN. Brasil.

E-mail: mgdimenstein@gmail.com

(1) https://orcid.org/0000-0002-5000-2915 


\section{Ana Carolina Rios Simoni}

Professora Adjunta do Departamento de Psicologia da Universidade Federal do Rio Grande do Norte, Doutora em Educação pela Universidade Federal do Rio Grande do Sul, Natal - RN. Brasil.

E-mail: anacarolrs@hotmail.com

(D) https://orcid.org/0000-0001-9805-6966

Mario Francis Petry Londero

Professor do Programa de Pós-Graduação em Psicologia da Universidade Federal do Rio Grande do Norte (UFRN), Natal - RN. Brasil. Dr. em Psicologia Social e Institucional pela Universidade Federal do Rio Grande do Sul.

E-mail: francislonder@hotmail.com

(D) https://orcid.org/0000-0003-2239-3899

Endereço para envio de correspondência:

Universidade Federal do Rio Grande do Norte, Departamento de Psicologia. Av. Senador Salgado Filho s/n. Lagoa Nova. CEP: 59078-970. Natal - RN. Brasil.

Recebido $27 / 08 / 2020$

Aceito 27/08/2020

Received $08 / 27 / 2020$

Approved 08/27/2020

Recibido 27/08/2020

Aceptado 27/08/2020

Como citar: Dimenstein, M., Simoni, A. C. R., \& Londero, M. F. P. (2020). Encruzilhadas da Democracia e da Saúde Mental em Tempos de Pandemia. Psicologia: Ciência e Profissão, 40, 1-16.

https://doi.org/10.1590/1982-3703003242817

How to cite: Dimenstein, M., Simoni, A. C. R., \& Londero, M. F. P. (2020). Crossroads of Democracy and Mental Health in Times of Pandemic. Psicologia: Ciência e Profissão, 40, 1-16.

https://doi.org/10.1590/1982-3703003242817

Cómo citar: Dimenstein, M., Simoni, A. C. R., \& Londero, M. F. P. (2020). Encrucijadas de la Democracia y la Salud Mental en Tiempos de Pandemia. Psicologia: Ciência e Profissão, 40, 1-16.

https:// doi.org/10.1590/1982-3703003242817 